\title{
Evaluation the oral hygiene conditions, oral Candida colonization and salivary Streptococcus mutans and Lactobacilli density in a group of $\beta$-thalassemic chil- dren and adolescence
}

\author{
Hüseyin Karayilmaz ${ }^{1}$, Hande Yalçin-Erman ${ }^{2}$, Özge Erken-Güngör ${ }^{1}$, Zeynep Öztürk ${ }^{3}$, Rasih Felek ${ }^{4}$, Alphan \\ Küpesiz $^{3}$
}

${ }^{1}$ Akdeniz University, Faculty of Dentistry, Department of Pedodontics.

${ }^{2}$ Antalya Oral and Dental Health Center

${ }^{3}$ Akdeniz University, Faculty of Medicine, Department of Pediatric Hematology-Oncology

${ }^{4}$ Akdeniz University, Faculty of Dentistry, Department of Microbiology

Correspondence:

Dr. Özge Erken Güngör

Akdeniz Universitesi, Dis Hekimligi Fakultesi

Pedodonti Anabilim Dal, Kampus, AntalyalTurkiye

erkentr@yahoo.com

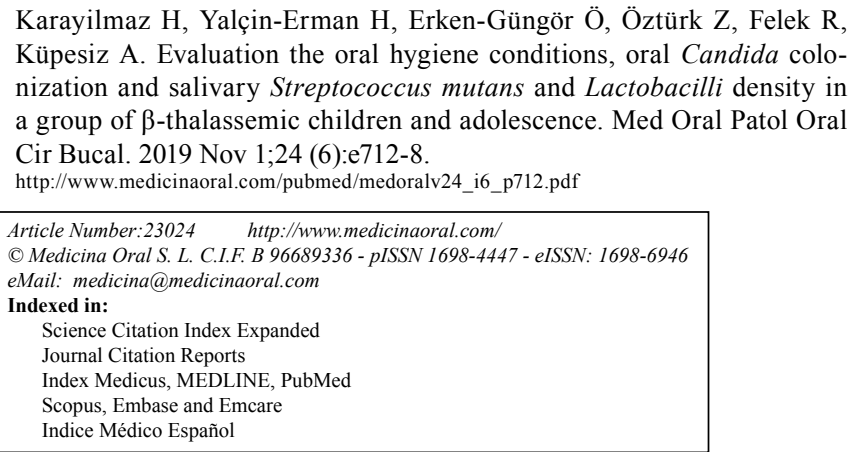

\begin{abstract}
Background: In this study, the prevalence and distribution of dental caries and oral hygiene conditions in a group of patients with $\beta$-TM are evaluated and the results compared to age-and gender-matched healthy patients. In addition, oral candida colonization and the density of Streptococcus mutans (S.mutans) and Lactobacilli in the total saliva are assessed.

Material and Methods: This study involved $59 \beta$-TM patients between 6-16 years old (mean:11.59 \pm 3.22 ), who applied to the Department of Pedodontics, Faculty of Dentistry, Akdeniz University, with ongoing follow-up, treatment and regular blood transfusions. All enrolled patients were diagnosed with $\beta$-TM by the Department of Pediatric Hematology and Oncology, Faculty of Medicine, Akdeniz University. As a control group, age-and gender-matched healthy 50 patients were included to the study.

Results: Plaque $(p=0.001)$, DMFT $(p=0.009)$ and DMFS $(p=0.039)$ indices were significantly higher in the $\beta$-TM patients, whereas, the oral hygiene status was significantly lower $(p=0.004)$. Saliva buffering capacity average was insignificantly but slightly more in $\beta$-TM patients $(p=0.131)$.

While S.mutans values were significantly higher in the $\beta$-TM patients $(p=0.002)$, no significant difference was found in the Lactobacillus ( $p=0.131$ ) and Candida values ( $p=0.33$ ).

Conclusions: DMFT, DMFS, Plaque and oral hygiene indices and S.mutans values were found significantly different in $\beta$-TM patients than healthy, control group patients, in this study.
\end{abstract}

Key words: Thalassemia major, DMFT, S.mutans, Lactobacilli, Candida. 


\section{Introduction}

Hemoglobin is the oxygen-transport protein in the red blood cells. Hemoglobin A is the major hemoglobin, comprising about $97 \%$ of the total hemoglobin. The structure of hemoglobin A typically consists of two alpha $(\alpha)$ and two beta $(\beta)$ globin chains $(1,2)$. The thalassemias are a group of genetic disorders characterized by decreased or absent production of globin chains, leading to microcytic anemia. The thalassemias are categorized according to the defective globin chain: $\alpha$-thalassemia and $\beta$-thalassemia. $\beta$-thalassemia is the most common genetic disorder worldwide (1-3), and is widespread in the Mediterranean countries, the Middle East, Central Asia, India, South China, the Far East, and on the northern coasts of Africa and South America. $\beta$-thalassemia is divided into three groups; thalassemia minor, thalassemia intermedia and thalassemia major (TM). Thalassemia minor is the carrier form of the disease, and carriers have asymptomatic mild-to-moderate microcytic anemia. Thalassemia intermedia patients present less severe clinical features than TM patients (13 ), and do not need regular blood transfusions, as they usually have hemoglobin levels of 7-10 g/dl (4). $\beta$-TM is also known as Cooley anemia or Mediterranean anemia. Patients with $\beta$-TM have severe microcytic hypochromic anemia, due to the reduced or absent production of $\beta$-globin chains, requiring repeated erythrocyte transfusions (2-4).

Children born with $\beta$-TM only show symptoms during the first year of life when adult hemoglobin has replaced fetal hemoglobin (5-8). Peripheral anemia arising from the disease sends signals to the bone marrow to increase the production of red blood cells, but the production of red blood cells is abnormal. With time, the marrow cavities expand (e.g., skull bones, facial bones, ribs), leading to characteristic facial features (referred to as "chipmunk" facies or "rodent-faced") and radiographic findings. If the disease is not treated, death can occur from anemia and congestive heart failure. The proper treatment for these patients includes routine blood transfusions and other therapies to survive (5-8).

The most common oro-facial features among thalassemia patients, because of intense compensatory hyperplasia of the marrow and expansion of the marrow cavity, are skeletal malocclusion, maxillary protrusion, mandibular atrophy, increased overjet, anterior open bite, prominence of the malar eminence, flat nose, lateral displacement of orbits and frontal bossing (5-8). Other dental features include flaring and spacing between maxillary incisors, cuspidal short roots, taurodontism, attenuated lamina dura and thin mandibular cortex (5-8). Additionally, thalassemic patients may have other oral symptoms, such as dental caries, due to the neglect of oral hygiene but also because of the decreasing concentrations of phosphorous and immunoglobulin A (Ig A) in saliva (5,6,8-15).
TM is one of the most common genetic disorders causing public health concern worldwide, including the Mediterranean region of Turkey. Nonetheless, a review of the literature demonstrates a lack of comprehensive studies regarding oro-facial features, dental caries and oral hygiene conditions of patients with TM.

In this study, the prevalence and distribution of dental caries and oral hygiene conditions in a group of patients with $\beta$-TM are evaluated and the results compared to age- and gender-matched healthy patients. In addition, oral Candida colonization and the density of Streptococcus mutans (S. mutans) and Lactobacilli in the total saliva are assessed.

\section{Material and Methods}

This study was supported by Akdeniz University, The Scientific Research Projects Coordination Unit, under the Project No: 2014.01.0151.002.

This case-control study involved $59 \beta$-TM patients between 6 and 16 years old, who applied to the Department of Pedodontics, Faculty of Dentistry, Akdeniz University, with ongoing follow-up, treatment and regular blood transfusions. All enrolled patients were diagnosed with $\beta$-TM by the Department of Pediatric Hematology/Oncology, Faculty of Medicine, Akdeniz University and had no systemic diseases, except TM. Patients who used antibiotics or anti-fungal medicines within the last 3 months and having splenectomy history, were excluded. As a control group, 50 patients between 6 and 16 years old, without any systemic disease, who applied to our clinics for routine dental treatments and did not use antibiotics and/or anti-fungal medicines within the last 3 months, were included. None of the patients enrolled in the study and control groups were smokers. Patients and parents were informed, and their written approvals were taken. Evaluations were carried out in the morning before any dental treatment was applied.

The Akdeniz University Research Ethics Committee approved the study (decision dated 12.02.2014 and numbered 113).

- Evaluation of Oral Hygiene

Oral hygiene (debris, calculus) status of the patients in the study and control groups was evaluated by the Simplified Oral Hygiene Index (16), which has two components: The Debris Index and the Calculus Index. Each of these indices is based on numerical determinations, representing the amount of debris or calculus found on the preselected tooth surfaces (16).

Plaque test (CRT Plaque Test, Ivoclar Vivadent, Liechtenstein) solution (a fluorescent disclosing liquid for the exposure of plaque) was used to evaluate the patients' plaque index, according to Silness and Löe (17).

A standard CRT buffer kit (CRT Buffer, Ivoclar Vivadent, Liechtenstein) was used to determine the saliva 
buffering capacity of the patient, by means of a test strip featuring a specific indicator system [yellow/ brown: $\mathrm{pH}<4.0$ (low), green: $\mathrm{pH}<4.5-5.5$ (medium), blue: $\mathrm{pH}>6.0$ (high)].

The tooth-level indices (DMFT/dft) and surface-level indices (DMFS/dfs) were calculated. The DMFT and DMFS indices are applied to the permanent dentition and are expressed as the total number of teeth or surfaces that are decayed (D), missing (M) or filled (F), in an individual, respectively. When written in lowercase letters, the $\mathrm{dft}$ and $\mathrm{dfs}$ indices are a variation that is applied to the primary dentition. Missing primary teeth should be ignored, because of the difficulty in distinguishing between teeth extracted due to caries and those that have naturally exfoliated.

- Microbiological Evaluation

In the morning, saliva samples stimulated with paraffin gum were collected from patients in the study and control groups, for microbiological evaluation. The patients were not allowed to eat or drink anything, chew any chewing gums, smoke, brush their teeth and use any mouthwashes, at least 1 hour before the test was conducted. Saliva samples, placed in sterile boxes, were homogeneously spread onto test kits (CRT Bacteria Refill, Ivoclar Vivadent, Liechtenstein) that have a selective medium for $S$. mutans and Lactobacillus on the respective sides. After incubation at $37^{\circ} \mathrm{C}$ for 48 hours, S. mutans and Lactobacillus were enumerated, according to the manufacturer's instructions.

\section{- Evaluation of Candidal Colonization}

Swab samples, which were taken with an applicator from the throat and cheek mucosa of study and control groups, were cultivated on a specific media with a loop (BD Sabouraud agar, including gentamicin and chloramphenicol), and incubated at $37^{\circ} \mathrm{C}$ for $24-28$ hours. Samples were taken from single colonies in the medium with a loop, and examined under a light microscope, by diluting with serum. Samples that were diagnosed with Candida were subcultured onto corn meal agar, Sabouraud dextrose agar and CHROMagar media. Candida spices were defined by API 20C AUX kits (BioMérieux, Marcy l'Etoile, France).

- Statistical Evaluation

Quantitative variables among the groups were compared using the Student's t-test, for parametric data. Nonparametric data were analyzed by the Kruskal-Wallis and Mann-Whitney U tests. Qualitative variables were examined with the Kruskal-Wallis, Mann-Whitney U, chi-square and exact Fisher tests, respectively. Statistical significance was assumed at $p<0.05$. All calculations were performed using SPSS 15.0 (SPSS Inc., Chicago, IL, USA).

\section{Results}

The study group consisted of $59 \beta$-TM patients (36 girls, 23 boys) aged between 6 and 16-years (mean: 11.59 \pm 3.22 years). The control group consisted of 50 patients, whose ages were the same range as those in the study group (mean: $11.06 \pm 2.86$ years). The study and control groups were divided into subgroups, according to permanent and mixed dentition periods, for evaluation.

In $\beta$-TM patients, the 21 patients in the mixed dentition subgroup were aged between 6 and 11 years (average: $8.04 \pm 1.71$ years) while the 38 patients in the permanent dentition subgroup were aged between 10 and 16 years (mean:13.55 \pm 1.91 years) (Fig. 1). In the control group, the 25 patients in the mixed dentition subgroup were aged 6-9 years (average: $7.4 \pm 1.04$ years) while the 25 patients in the permanent dentition subgroup were 1216 years old (mean: $12.72 \pm 0.93$ years) (Fig. 1).

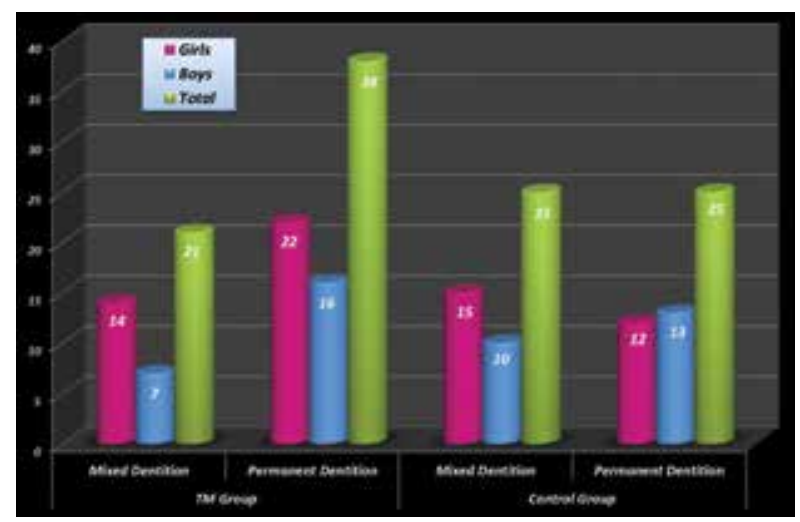

Fig. 1: Distribution of $\beta-\mathrm{TM}$ and control group patients according to gender and dentition.

\section{- Evaluation of Oral Hygiene}

The DMFT, DMFS, dft and dfs ratios obtained from the $\beta$-TM and control group patients (and from subgroups, mixed and permanent dentition) have been summarized in Table 1, and the oral hygiene statuses, plaque indices and saliva buffering capacities have been summarized in Table 2. In comparison to the control group, the plaque, DMFT and DMFS indices were significantly higher in the $\beta$-TM patients (plaque index: $p=0.001$; DMFT index: $p=0.009$; DMFS $p=0.039$ ) (Table 1), whereas, the oral hygiene status was significantly lower in $\beta$-TM (oral hygiene index: $p=0.004$ ). Although the saliva buffering capacity average was slightly more in $\beta$-TM patients than the control group, the difference was not significant (saliva buffering capacity: $p=0.131$ ) (Table 2).

When gender differences in the $\beta$-TM patients and control group were considered, only the plaque indices of male $\beta$-TM patients were found to be higher $(p=0.002)$. No significant relationship was found in other parameters $(p>0.05)$ (Table 2). 
Table 1: The results of DMFT, DMFS, dft, and dfs indexes.

\begin{tabular}{|c|c|c|c|c|c|c|c|c|c|c|c|c|c|}
\hline & \multicolumn{3}{|c|}{ DMFT } & \multicolumn{3}{|c|}{ DMFS } & \multicolumn{3}{|c|}{ dft } & \multicolumn{3}{|c|}{ dfs } \\
\hline & & Min. & Max. & Mean & Min. & Max. & Mean & Min. & Max. & Mean & Min. & Max. & Mean \\
\hline \multirow{2}{*}{$\begin{array}{c}\beta \text {-TM } \\
\text { Group }\end{array}$} & $\begin{array}{c}\text { Mixed } \\
\text { Dentition }\end{array}$ & 0 & 4 & $\begin{array}{c}1.71 \\
\pm 1.67\end{array}$ & 0 & 7 & $\begin{array}{c}2.04 \\
\pm 2.17\end{array}$ & 0 & 8 & $\begin{array}{c}3.8 \\
\pm 2.52\end{array}$ & 0 & 17 & $\begin{array}{c}6.04 \\
\pm 4.75\end{array}$ \\
\hline & $\begin{array}{c}\text { Permanent } \\
\text { Dentition }\end{array}$ & 0 & 11 & $\begin{array}{c}4.92 \\
\pm 2.64\end{array}$ & 0 & 27 & $\begin{array}{c}6.55 \\
\pm 4.89\end{array}$ & - & - & - & - & - & - \\
\hline \multicolumn{2}{|c|}{ Total } & 0 & 11 & $\begin{array}{c}3.77 \\
\pm 2.79\end{array}$ & 0 & 27 & $\begin{array}{c}4.94 \\
\pm 4.65\end{array}$ & - & - & - & - & - & - \\
\hline \multirow{2}{*}{$\begin{array}{c}\text { Control } \\
\text { Group }\end{array}$} & $\begin{array}{c}\text { Mixed } \\
\text { Dentition }\end{array}$ & 0 & 8 & $\begin{array}{l}1.56 \\
\pm 2.2\end{array}$ & 0 & 14 & $\begin{array}{c}2.2 \\
\pm 3.61\end{array}$ & 0 & 10 & $\begin{array}{c}5.2 \\
\pm 2.46\end{array}$ & 0 & 19 & $\begin{array}{c}8.6 \\
\pm 4.79\end{array}$ \\
\hline & $\begin{array}{c}\text { Permanent } \\
\text { Dentition }\end{array}$ & 0 & 7 & $\begin{array}{c}3.36 \\
\pm 1.97\end{array}$ & 0 & 11 & $\begin{array}{c}4.4 \\
\pm 3.26\end{array}$ & - & - & - & - & - & - \\
\hline \multicolumn{2}{|c|}{ Total } & 0 & 8 & $\begin{array}{c}2.46 \\
\pm 2.26\end{array}$ & 0 & 14 & $\begin{array}{c}3.3 \\
\pm 3.58\end{array}$ & - & - & - & - & - & - \\
\hline
\end{tabular}

(DMFT; $p=0.009$, DMFS; $p=0.039$, Mixed Dentition; $p>0.05$, Permanent Dentition DMFT; $p=0.014$, DMFS; $p>0.05$ )

Table 2: The results of Plaque Index, Oral Hygiene Index and Saliva Buffering Capacity.

\begin{tabular}{|c|c|c|c|c|c|c|c|c|c|c|c|}
\hline & \multicolumn{3}{|c|}{ Plaque Index } & \multicolumn{3}{|c|}{ Oral Hygiene Index } & \multicolumn{3}{|c|}{ Saliva Buffering Capacity } & \multirow{2}{*}{ Total } \\
\hline & & Good & Med. & Poor & Good & Med. & Poor & Low & Med. & High & \\
\hline \multirow{2}{*}{$\begin{array}{c}\beta \text {-TM } \\
\text { Group }\end{array}$} & $\begin{array}{c}\text { Mixed } \\
\text { Dentition }\end{array}$ & $\begin{array}{c}13 \\
22 \%\end{array}$ & $\begin{array}{c}7 \\
11.9 \%\end{array}$ & $\begin{array}{c}1 \\
1.7 \%\end{array}$ & $\begin{array}{c}2 \\
3.4 \%\end{array}$ & $\begin{array}{c}19 \\
32.2 \%\end{array}$ & $\begin{array}{c}0 \\
0 \%\end{array}$ & $\begin{array}{c}0 \\
0 \%\end{array}$ & $\begin{array}{c}5 \\
8.5 \%\end{array}$ & $\begin{array}{c}16 \\
27.1 \%\end{array}$ & $\begin{array}{c}21 \\
35.6 \%\end{array}$ \\
\hline & $\begin{array}{c}\text { Permanent } \\
\text { Dentition }\end{array}$ & $\begin{array}{c}14 \\
23.7 \%\end{array}$ & $\begin{array}{c}20 \\
33.9 \%\end{array}$ & $\begin{array}{c}4 \\
6.8 \%\end{array}$ & $\begin{array}{c}3 \\
5.1 \%\end{array}$ & $\begin{array}{c}35 \\
59.3 \%\end{array}$ & $\begin{array}{c}0 \\
0 \%\end{array}$ & $\begin{array}{c}2 \\
3.4 \%\end{array}$ & $\begin{array}{c}7 \\
11.9 \%\end{array}$ & $\begin{array}{c}29 \\
49.2 \%\end{array}$ & $\begin{array}{c}38 \\
64.4 \%\end{array}$ \\
\hline \multicolumn{2}{|c|}{ Total } & $\begin{array}{c}27 \\
45.8 \%\end{array}$ & $\begin{array}{c}27 \\
45.8 \%\end{array}$ & $\begin{array}{c}5 \\
8.5 \%\end{array}$ & $\begin{array}{c}5 \\
8.5 \%\end{array}$ & $\begin{array}{c}54 \\
91.5 \%\end{array}$ & $\begin{array}{c}0 \\
0 \%\end{array}$ & $\begin{array}{c}2 \\
3.4 \%\end{array}$ & $\begin{array}{c}12 \\
20.3 \%\end{array}$ & $\begin{array}{c}45 \\
76.3 \%\end{array}$ & $\begin{array}{c}59 \\
100 \%\end{array}$ \\
\hline \multirow{2}{*}{$\begin{array}{l}\text { Control } \\
\text { Group }\end{array}$} & $\begin{array}{c}\text { Mixed } \\
\text { Dentition }\end{array}$ & $\begin{array}{c}19 \\
38 \%\end{array}$ & $\begin{array}{c}6 \\
12 \%\end{array}$ & $\begin{array}{c}0 \\
0 \%\end{array}$ & $\begin{array}{c}7 \\
14 \%\end{array}$ & $\begin{array}{c}18 \\
36 \%\end{array}$ & $\begin{array}{c}0 \\
0 \%\end{array}$ & $\begin{array}{c}1 \\
2 \%\end{array}$ & $\begin{array}{c}10 \\
20 \%\end{array}$ & $\begin{array}{c}14 \\
28 \%\end{array}$ & $\begin{array}{c}25 \\
50 \%\end{array}$ \\
\hline & $\begin{array}{c}\text { Permanent } \\
\text { Dentition }\end{array}$ & $\begin{array}{c}18 \\
36 \%\end{array}$ & $\begin{array}{c}75 \\
14 \%\end{array}$ & $\begin{array}{c}0 \\
0 \%\end{array}$ & $\begin{array}{c}8 \\
16 \%\end{array}$ & $\begin{array}{c}17 \\
34 \%\end{array}$ & $\begin{array}{c}0 \\
0 \%\end{array}$ & $\begin{array}{c}0 \\
0 \%\end{array}$ & $\begin{array}{c}8 \\
16 \%\end{array}$ & $\begin{array}{c}17 \\
34 \%\end{array}$ & $\begin{array}{c}25 \\
50 \%\end{array}$ \\
\hline \multicolumn{2}{|c|}{ Total } & $\begin{array}{c}37 \\
74 \%\end{array}$ & $\begin{array}{c}13 \\
26 \%\end{array}$ & $\begin{array}{c}0 \\
0 \%\end{array}$ & $\begin{array}{c}15 \\
30 \%\end{array}$ & $\begin{array}{c}35 \\
70 \%\end{array}$ & $\begin{array}{c}0 \\
0 \%\end{array}$ & $\begin{array}{c}1 \\
2 \%\end{array}$ & $\begin{array}{c}18 \\
36 \%\end{array}$ & $\begin{array}{c}31 \\
62 \%\end{array}$ & $\begin{array}{c}50 \\
100 \%\end{array}$ \\
\hline
\end{tabular}

(Plaque Index; $p=0.001$, Mixed Dentition; $p>0.05$, Permanent Dentition; $p=0.005$ )

(Oral Hygiene Index; $p=0.004$, Mixed Dentition; $p=0.047$, Permanent Dentition; $p=0.023$ )

(Saliva Buffering Capacity; $p>0.05$, Mixed Dentition; $p>0.05$, Permanent Dentition; $p>0.05$ )

- Mixed Dentition

A significant difference was only observed in the oral hygiene index, among the parameters examined during the mixed dentition period. The oral hygiene index was lower in $\beta$-TM patients than control group patients (oral hygiene index: $p=0.047$ ) (Table 2).

- Permanent Dentition

Plaque index, oral hygiene index and DMFT index values were shown to be significantly higher in $\beta$-TM patients than the control group, during the permanent dentition period (DMFT index: $p=0.014$; plaque index: $p=0.005$; oral hygiene index: $p=0.023$ ). There was no significant difference in the DMFS index and saliva buffering capacity between the $\beta$-TM and control patients (DMFS: $p=0.058$; saliva buffering capacity: $p=0.567$ ) (Table 1, Table 2 ).

- Microbiological Evaluation

S. mutans and Lactobacillus values obtained from $\beta$-TM and control group patients (and from subgroups, mixed and permanent dentition) have been summarized in Table 3. While $S$. mutans values were significantly higher in the $\beta$-TM patients than the control group $(S$. mutans: $p=0.002$ ), no significant difference was found in the Lactobacillus values between these two groups (Lactobacillus: $p=0.131$ ) (Table 3 ). A statistically significant effect of gender was not evident $(p>0.05)$.

- Mixed Dentition

No significant relationship was seen in the $S$. mutans and Lactobacillus values between the two groups during the mixed dentition period (S. mutans: $p=0.86$; Lactobacillus: $p=0.418$ ) (Table 3).

- Permanent Dentition

$S$. mutans values were statistically higher in $\beta$-TM patients in the permanent dentition period when compared to the control group $(p=0.008)$. No significant difference in Lactobacillus values appeared between the two groups (Lactobacillus: $p=0.507$ ) (Table 3). 
Table 3: Distribution of Streptococcus mutans, Lactobacillus values.

\begin{tabular}{|c|c|c|c|c|c|c|c|c|}
\hline & \multicolumn{3}{|c|}{ Streptococcus mutans } & \multicolumn{3}{|c|}{ Lactobacillus } & \multirow[t]{2}{*}{ Total } \\
\hline & & High & Med. & Low & High & Med. & Low & \\
\hline \multirow{2}{*}{$\begin{array}{l}\beta \text {-ТМ } \\
\text { Group }\end{array}$} & $\begin{array}{c}\text { Mixed } \\
\text { Dentition }\end{array}$ & $\begin{array}{c}12 \\
20.3 \%\end{array}$ & $\begin{array}{c}6 \\
10.2 \%\end{array}$ & $\begin{array}{c}3 \\
5.1 \%\end{array}$ & $\begin{array}{c}6 \\
10.2 \%\end{array}$ & $\begin{array}{c}6 \\
10.2 \%\end{array}$ & $\begin{array}{c}9 \\
15.3 \%\end{array}$ & $\begin{array}{c}21 \\
35.6 \%\end{array}$ \\
\hline & $\begin{array}{c}\text { Permanent } \\
\text { Dentition }\end{array}$ & $\begin{array}{c}23 \\
39 \%\end{array}$ & $\begin{array}{c}8 \\
13.6 \%\end{array}$ & $\begin{array}{c}7 \\
11.9 \%\end{array}$ & $\begin{array}{c}3 \\
5.1 \%\end{array}$ & $\begin{array}{c}13 \\
22 \%\end{array}$ & $\begin{array}{c}22 \\
37.3 \%\end{array}$ & $\begin{array}{c}38 \\
64.4 \%\end{array}$ \\
\hline \multicolumn{2}{|c|}{ Total } & $\begin{array}{c}35 \\
59.3 \%\end{array}$ & $\begin{array}{c}14 \\
23.7 \%\end{array}$ & $\begin{array}{c}10 \\
16.9 \%\end{array}$ & $\begin{array}{c}9 \\
15.3 \%\end{array}$ & $\begin{array}{c}19 \\
32.2 \%\end{array}$ & $\begin{array}{c}31 \\
52.5 \%\end{array}$ & $\begin{array}{c}59 \\
100 \%\end{array}$ \\
\hline \multirow{2}{*}{$\begin{array}{l}\text { Control } \\
\text { Group }\end{array}$} & $\begin{array}{c}\text { Mixed } \\
\text { Dentition }\end{array}$ & $\begin{array}{c}7 \\
14 \%\end{array}$ & $\begin{array}{c}13 \\
26 \%\end{array}$ & $\begin{array}{c}5 \\
10 \%\end{array}$ & $\begin{array}{c}7 \\
14 \%\end{array}$ & $\begin{array}{c}12 \\
24 \%\end{array}$ & $\begin{array}{c}6 \\
12 \%\end{array}$ & $\begin{array}{c}25 \\
50 \%\end{array}$ \\
\hline & $\begin{array}{c}\text { Permanent } \\
\text { Dentition }\end{array}$ & $\begin{array}{c}6 \\
12 \%\end{array}$ & $\begin{array}{c}10 \\
20 \%\end{array}$ & $\begin{array}{c}9 \\
18 \%\end{array}$ & $\begin{array}{c}4 \\
8 \%\end{array}$ & $\begin{array}{c}8 \\
16 \%\end{array}$ & $\begin{array}{c}13 \\
26 \%\end{array}$ & $\begin{array}{c}25 \\
50 \%\end{array}$ \\
\hline \multicolumn{2}{|c|}{ Total } & $\begin{array}{c}13 \\
26 \%\end{array}$ & $\begin{array}{c}23 \\
46 \%\end{array}$ & $\begin{array}{c}14 \\
28 \%\end{array}$ & $\begin{array}{c}11 \\
22 \%\end{array}$ & $\begin{array}{c}20 \\
40 \%\end{array}$ & $\begin{array}{c}19 \\
38 \%\end{array}$ & $\begin{array}{c}50 \\
100 \%\end{array}$ \\
\hline
\end{tabular}

(Streptococcus mutans; $p=0.002$, Mixed Dentition; $p>0.05$, Permanent Dentition; $p=0.008)($ Lactobacillus; $p>0.05)$.

\section{- Evaluation of Candidal Colonization}

Although, it was not observed in 44 of the $\beta$-TM patients (74.6\%), Candida was seen only in 15 patients. After the typing process, Candida albicans was detected in 14 patients (23.7\%), and Candida glabrata was identified in 1 patient (1.7\%). In the control group, Candida occurred in 33 out of the 50 patients (66\%). Candida albicans was found in 16 of these patients and Candida parapsilosis in 1 patient, following the typing process. There was no significant correlation in the Candida values between the study and control groups $(p=0.33)$. Given the low Candida evaluation rate of patients in the study and control groups, the patients in the subgroups (mixed and permanent dentition) were not evaluated.

\section{Discussion}

Oral and dental problems and their treatments affect the general health of the human body. Especially in people with systemic problems, oral and dental issues must be evaluated, and certain procedures must be carefully followed for treatment. The oral hygiene status must be examined, and decay activities of the patients must be defined in at-risk patients, such as TM patients.

A limited number of studies are currently available on the oral and dental problems of TM patients. Whereas some of the studies asserted that the decay frequency of TM patients was higher when compared to healthy people, some reports claim that there were not any differences (6,9-11).

Lugliè et al. (9) evaluated the oral hygiene indices, $S$. mutans levels and DMTF indices of $18 \mathrm{TM}$ patients aged between 23 and 31 years, and 18 control group patients in the same age range, in 2002. The authors stated that $S$. mutans values were significantly higher in TM patients when compared to control group, and, although the DMFT indices were higher in TM patients (TM: DMFT $=10.3$; control: DMFT $=9.4$ ), this difference was not significant. In addition, no statistically meaning- ful difference in the oral hygiene indices between the two groups was determined while plaque existence was higher in the control group patients.

In the same year, Al-Wahadni et al. (10) analyzed DMFT, plaque and gingival index values in a study of $61 \beta$-TM patients and 63 control patients aged 6-12 and 13-18-years. The results revealed that the DMTF indices were significantly higher in $\beta$-TM patients for both of the age groups. Plaque and gingival index values were also higher in $\beta$-TM patients, in both age groups, but it was not significant.

In 2001, Hattab et al. (11) examined the plaque scores and DMFT/dmft values of $54 \mathrm{TM}$ patients aged between 6 and 18 years. The dmft ratio was 6.92 for $6-7$-yearolds, and 4.72 for 8-9-year-olds, and the DMFT ratio was 6.57 for 12-14-year-olds, and 5.95 for those in the 15-18-year age group, respectively. No significant relationship between the patient groups during the temporary and permanent dentition periods was reported. The authors documented a high plaque score in $61.1 \%$ of the TM patients and described the patients as having poor oral hygiene status.

Recently, Al-Raeesi et al. (6) comparatively assessed the DMFT/dmft indices, oral hygiene index, occlusal anomalies, dentofacial and soft-tissue abnormalities in a total of $38 \beta$-TM and 76 healthy Emirati children. The children with $\beta$-TM had a significantly higher DMFT and calculus index compared to the healthy controls, but a significantly lower gingivitis proportion.

In our study, the $S$. mutans counts, and the DMFT, plaque and oral hygiene indices of $59 \beta-\mathrm{TM}$ and 50 control patients, aged between 6 and 16 years, were investigated. In accordance with Luglie et al. (9), the $S$. mutans levels in our study were significantly higher in the $\beta$-TM group when compared with the control group. The DMFT indices were significantly higher in $\beta$-TM patients than the control group, which concurred with the studies of Al-Raeesi et al. (6) and Al-Wahadmi et 
al. (10), but the data presented by Luglie et al. (9) were comparatively lower. Al-Wahadmi et al. (10), stated that DMFT ratios increased together with age in their study. In the current work, the plaque and oral hygiene index values were statistically higher in the $\beta$-TM patients, contrary to the research by Luglie et al. (9) and Al-Wahadmi et al. (10). The study carried out by Hattab et al. (8), reported that more than half of TM patients had a high plaque score. The differences between these studies and our work could originate from several parameters, such as the preferred study methods, and regional and socioeconomic factors.

Lactobacillus, which is responsible for dentin decay, was also examined in our study and no significant association occurred between the $\beta$-TM and control groups. According to the scanning results of available resources, no other studies have previously explored the saliva Lactobacillus densities of $\beta$-TM patients. There is a need for extensive studies to examine salivary $S$. mutans and Lactobacillus densities of $\beta$-TM patients.

When investigating the relationship between decay and gender in $47 \mathrm{TM}$ patients, Leonardi et al. (18), noticed a higher decay prevalence in male TM patients. However, in Hattab et al. (11), and our study, a significant effect of gender was not determined.

Literature studies suggest the gingivitis occurrence frequency can be higher in TM patients than healthy individuals, and this can result from local factors or oralmaxillo-facial features of the disorder $(9,11,12,19)$. In 2007, Ay et al. (20), compared to the blood lipid levels and periodontal parameters (gingival index, plaque index, probing bleeding, probing depth) in $24 \mathrm{TM}$ patients with 20 age-matched control patients, and found that all periodontal parameters were significantly higher in the TM patients. Siamopoulou-Mavridou et al. (12), examined the gingivitis and decay experiences, as well as the flow rate, calcium, phosphorous, potassium, sodium, urea and lysozyme immunoglobulin levels (IgA, IgG, IgM) of the saliva of $21 \mathrm{TM}$ and 83 control patients. According to the results, gingivitis and decay prevalence were statistically higher in TM patients. No significant difference was found in the flow rate of saliva while phosphorous and IgA were significantly lower in TM patients.

One of the aims of our study was to assess the decay tendency levels, by comparing saliva buffering capacities of $\beta$-TM and control patients, and no significant relationship was determined. To the best of our knowledge, no other current studies have analyzed the saliva buffering capacities of TM patients.

Multiple immune disorders can be seen in TM patients, which can create a predisposing effect for oral Candida (21-23). Candida types are opportunistic pathogens that exist in normal oral flora but can cause serious infections when the immune system is weakened. Candida albicans is mentioned in the literature as the most isolated type, both in healthy people and TM patients (2123).

In 2010, Hazza'a et al. (23) surveyed oral Candida carriers within $50 \beta-\mathrm{TM}$ and 50 control patients by the mouthwash method. Candida was isolated in $74 \%$ $(n=37)$ of the TM patients and $56 \%(n=28)$ of the control group, and the difference was significant.

In our study, Candida was isolated in $25.4 \%$ (15 patients) of $\beta$-TM patients and 34\% (17 patients) of control patients and, according to our results, no significant relationship was evident between the study and control groups. Less Candida was isolated in $\beta$-TM patients in our study when compared with the study of Hazza'a et al. (23), probably due to differences in the methods used since Hazza'a et al. (23) preferred the mouthwash technique as the sample collection method, whereas, in our study, swab samples from the cheek and soft palate regions were collected. Socioeconomic, regional and other differences could be other factors contributing to the discrepancy.

To date, there are limited numbers of studies on oral Candida colonization of TM patients in the literature. Extensive studies are required, considering the occurrence possibility of Candida, among TM patients accompanied by multiple immune disorders.

The prevalence of $\beta$-TM patients in Antalya Province (West Mediterranean Region of Turkey) (12-13.1\%) is above Turkeys' average, so regular and strict treatment/ follow-up protocols are carried out for $\beta$-TM patients in this region (24). This scenario allows envisaging the complications (e.g., oro-facial deformities, infections of the immune system, Candida infection) that can be experienced in $\beta$-TM patients. Educative and informative programs about treatment and follow-up of the disorder have been conducted regularly, for primary protection, as part of the treatment protocol.

As a conclusion, oro-dento-facial problems can be prevented before they occur, providing close examination by a dentist at diagnosis, treatment and follow-up of TM patients, beginning from childhood. Especially, pediatric dentists have a major preventive role in these problems. It is important that hematologists and pediatric dentists work together during treatment and follow-up procedures of TM patients. Informative and educative programs for TM patients and their parents must be provided by pediatric dentists, addressing complications which can occur in oro-dento-facial structures, as well as solutions and considerations. 


\section{References}

1. Weatherall DJ, Pressley L, Wood WG, Higgs DR, Clegg JB. Molecular basis for mild forms of homozygous beta-thalassaemia. Lancet 1.1981;8219:527-9.

2. Weatherall DJ, Clegg JB. The $\beta$ thalassaemias. In: The thalassaemia syndromes. Oxford: Blackwell Science. 1981;p:149-56.

3. Garewal G, Das R, Awasthi A, Ahluwalia J, Marwaha RK. The clinical significance of the spectrum of interactions of CAP+1 (A$->$ C), a silent beta-globin gene mutation, with other beta-thalassemia mutations and globin gene modifiers in north Indians. Eur J Haematol. 2007;79:417-21.

4. Karimi M, Cohan N, De Sanctis V, Mallat NS, Taher A. Guidelines for diagnosis and management of Beta-thalassemia intermedia. Pediatr Hematol Oncol. 2014;31:583-96.

5. Madhok S, Madhok S. Dental considerations in Thalassemic patients. IOSR-JDMS. 2014;13:57-62.

6. Al-Raeesi S, Kowash M, Hassan A, Al-Halabi M. Oral manifestations and dentofacial anomalies in $\beta$-thalassemia major children in Dubai (UAE). Spec Care Dentist. 2018;38(1):25-30.

7. AlDallal S, AlKathemi M. Orodental Considerations in Thalassemia Patients. J Hematol Blood Disord. 2016;2:205-11.

8. Kaplan R, Werther R, Castano F. Dental and oral findings in Cooley's anemia: a study of fifty cases. Ann N Y Acad Sci. 1964;119:664-6. 9. Luglie PF, Campus G, Deiola C, Mela MG, Gallisai D. Oral condition, chemistry of saliva, and salivary levels of Streptococcus mutans in thalessemic patients. Clin Oral Invest. 2002;6:223-6.

10. Al-Wahadni AM, Taani DQ, Al-Omari MO. Dental diseases in subjects with beta-thalassemia major. Community Dent Oral Epidemiol. 2002;30:418-22.

11. Hattab FN, Hazza'a AM, Yassin OM, al-Rimavi HS. Caries risk in patients with thalassemia major. Int Dent J. 2001;51:35-8.

12. Siamopoulou-Mavridou A, Mavridis A, Galanakis E, Vasakos S, Fatourou H, Lapatsanis P. Flow rate and chemistry of parotid saliva related to dental caries and gingivitis in patients with thalassemia major. Int J Paediatr Dent. 1992;2:93-7.

13. Kataria SK, Arora M, Dadhich A, Kataria KR. Orodental complications and orofacial manifestation in children and adolescents with thalassaemia major of western Rajasthan population: a comparative study. Int J Biol Med Res. 2012;3:1816-9.

14. Kaur N, Hiremath S. Dental caries and gingival status of 3-14-year-old beta thalassemia major patients attending paediatric OPD of Vani Vilas Hospital. Arch Oral Sci Res. 2012;2:67-70.

15. Pedullà E, Scibilia M, Saladdino G, Colletta G. Dental and periodontal condition in patients affected by $\beta$-thalassemia major and $\beta$ -thalassemia intermedia: a study among adults in Sicily, Italy. J Dent Heal Oral Disord Ther. 2015;3:383-5.

16. Greene JC, Vermillion JR. The Simplified Oral Hygiene Index. J Am Dent Assoc. 1964;68:7-13.

17. Silness J, Löe H. Periodontal disease in pregnancy II-correlation between oral hygiene and periodontal condition. Acta Odontol Scand. 1964;22:121-35.

18. Leonardi R, Verzi P, Caltabiano M. Epidemiological survey of the prevalence of dental caries in young thalessemia major patients. Stomatol Mediterr. 1990;10:133-6.

19. Bucci E, Lo Muzio L, Mignogna M. D, Caparrotti M. Beta-thalassemia and its orodental implications. II. A clinical study. Minerva Stomatol. 1990;39:9-13.

20. Ay ZY, Oruçoglu A, Kilinç G, Oztürk M, Kilbaş A, Uskun E, Bozkurt FY, Canatan D. Does the periodontal health of thalassemia major patients have an impact on the blood lipid profiles? A preliminary report. J Pediatr Hematol Oncol. 2007;29:694-9.

21. Skoutelis AT, Lianou E, Papavassiliou T, Karamerou A, Politi K. Bassaris HP. Defective phagocytic and bactericidal function of polymorphonuclear leukocytes in patients with beta-thalassaemia major. J Infect. 1984;8:118-22.

22. Oyefara BI, Kim HC, Danziger RN, Carroll M, Greene JM, Douglas SD. Autoimmune hemolytic anemia in chronic mucocutaneous candidiasis. Clin Diagn Lab Immunol. 1991;1:38-43.
23. Hazza'a AM, Darwazeh AM, Museedi OS. Oral Candida flora in a group of Jordanian patient with beta-thalassemia major. Oral Surg Oral Med Oral Pathol Oral Radiol Endod. 2010;109:252-6.

24. Canatan D. Dünyada ve Türkiye'de talasemi ve anormal hemoglobinler. Talasemi ve Hemoglabinopatiler. UHK. 2004;p:11-4.

\section{Funding}

None declared.

\section{Conflict of interest}

None declared. 